\title{
El diario del mayor $X$, informe clasificado del Descubrimiento y la (Re)Conquista de las Islas Malvinas (en Las Islas, Carlos Gamerro)
}

\author{
Laura DESTÉFANIS \\ destefanis@ugr.es \\ Universidad de Granada
}

\begin{abstract}
RESUMEN
La novela Las Islas (Carlos Gamerro, 1998) recorre y desarma los discursos de poder que han constituido al Estado argentino, con foco en la guerra de Malvinas y la democracia neoliberal de fines del siglo XX. Este trabajo analiza el diario del mayor X, deformado por el daño psíquico del soldado conscripto que recibió la orden de memorizarlo en plena guerra. El mayor es el militar prototípico que interviene tanto en Malvinas como en la así llamada "guerra sucia", esto es, la represión bajo dictadura que sistematizó el circuito criminal de secuestro y desaparición. En su diario, Gamerro parodia los relatos de cronistas y exploradores de América y revisita en clave irónica la historiografía republicana.
\end{abstract}

Palabras clave: Malvinas, Gamerro, diario, cronistas, parodia.

Major X's diary, a classified report of Discovering and (Re)Conquest of the Islands (in Carlos Gamerro's The Islands)

\begin{abstract}
The Islands (Carlos Gamerro, 1998) traces and reveals the discourses of power that have constituted the Argentine State. This paper analyzes the diary of major X, deformed by the psychic-damaged conscript who received the order of knowing it by heart during the war. Major X is the prototypical serviceman involved not only in the Falklands war but also in the so-called "dirty war", i.e. repression under dictatorship that systematized the criminal circuit of kidnapping, torture and disappearance. His diary is a parody of the tales of chroniclers and explorers of the American continent and an ironical revision of republican historiography.
\end{abstract}

Keywords: Falklands, Gamerro, diary, chroniclers, parody.

Carlos Gamerro ha publicado cinco novelas entre 1998 y 2011. Ya en la primera, Las Islas, realiza un recorrido exhaustivo y demoledor por la historia argentina con especial atención a sus núcleos traumáticos. Las Islas es una lectura de los años noventa desde la guerra de Malvinas (1982) y sus consecuencias, a diez años de ocurrida (Gamerro comienza a escribir la novela en 1992), que deja como saldo de lectura un efecto invalorable: la erosión de los cimientos ideológicos sobre los que 
se estructuró el proyecto nacional que constituyó a la Argentina desde 1853 hasta el presente, trabajo sobre la historia y la tradición que fue ampliado en cada una de las novelas que publicó más tarde. Mi propósito es presentar una pieza de todo este engranaje de largo aliento, que a modo de sinécdoque nos permita considerar los alcances de esta literatura.

La complejidad de Las Islas permite realizar diferentes recorridos de lectura que no agotan su significación. Es una novela policial, trágica y a la vez humorística (Kohan, 1999), en la que parodia, ironía y sátira se solapan continuamente. Felipe Félix (el protagonista), hacker y excombatiente en la guerra de Malvinas, es contratado por el poderoso empresario Fausto Tamerlán para ocultar las pruebas de un crimen. De camino, le pide además información acerca del paradero de su primogénito, también soldado en la guerra de Malvinas, de cuya suerte nunca se supo. Su cuerpo, como el de tantos otros excombatientes, continúa desaparecido. Para averiguarlo, Felipe Félix tendrá que secuestrar el diario del mayor X, con valiosa información acerca de la guerra.

¿Quién es el mayor X? En Las Islas, es el nom de guerre de Antonio Cuervo, prototipo del militar que actuó en el conflicto dejando saber su comprometida participación en lo que algunos llamaron 'guerra sucia', esto es, la represión interna desatada años antes del golpe militar de 1976 y sistematizada a partir de entonces mediante un circuito de secuestro, tortura y desaparición. El colofón de los años de represión fue Malvinas, la 'guerra limpia', según la expresión que acunó León Rozitchner para denunciar la maniobra argentina (Rozitchner, 2006). La guerra de Malvinas evidenció el tipo de entrenamiento militar de las Fuerzas Armadas argentinas: efectividad absoluta para la represión interna y un altísimo nivel de imprevisión y negligencia para la guerra en sentido llano.

El apodo 'mayor X' presenta un alto grado de significación por un juego de intertextualidad y referencia con las series literaria, política y social: mayor X es un oscuro personaje del célebre cuento de Rodolfo Walsh "Esa mujer" (Walsh, 1996: 9-19), en el que un periodista - alter ego del autor-entrevista a un militar para averiguar el paradero del desaparecido cuerpo de Eva Perón, mediante lo que más tarde se conoció como Operación Evasión (Bauer, 1997). Es un hecho notable que el cadáver que inauguraría la serie de desapariciones en la historia política argentina contemporánea fuera el de Evita, tras el golpe de Estado a Perón en 1955, hecho que aparece magistralmente condensado en la obra poética de Néstor Perlongher (1997): "El cadáver" (Austria-Hungría, 1980), "Cadáveres" (Alambres, 1987), "El cadáver de la nación" (en Hule, 1989), entre otros textos. Cuando Walsh escribe el cuento -entre 1961 y 1964-, esta desaparición seguía siendo una incógnita: el mayor $\mathrm{X}$ aparece envuelto, como su nombre indica, en la 'incógnita mayor' de este secuestro. Notable es también que, en 1977, el propio Rodolfo Walsh se convirtiera en uno de los desaparecidos de la última dictadura, entre otros treinta mil a los que se suman los cuerpos NN enterrados en las islas. El nombre de Walsh simboliza desde entonces la relación entre literatura y compromiso político en Argentina, a 
pesar de que podría aducirse que Ernesto Guevara lo supera, aunque la dimensión de su figura excede ampliamente el marco nacional. Sus escritos, además, se han visto relegados por su actividad revolucionaria. Ya Piglia recogía su rol de lector (Piglia, 2005: 103-138), pero es el propio Gamerro, en cuya obra los diarios y la figura del Che tienen una presencia de peso (Gamerro, 1998, 2004, 2011, 2015), quien lo reconoce así como escritor:

El más famoso de los escritores argentinos es el gran ausente de la literatura argentina, a pesar de que sus cuatro obras narrativas, Diarios de motocicleta, Pasajes de la guerra revolucionaria: Cuba, Pasajes de la guerra revolucionaria: Congo y, sobre todo, Diario del Che en Bolivia figuran, a nivel mundial, entre las más leídas y comentadas. Me refiero, por supuesto, a Ernesto Che Guevara. Sí, ya escucho la primera objeción: el Che Guevara no es famoso por su literatura. A lo que yo respondo, ¿tan seguros están? [...] Otra objeción posible, y otra posible respuesta, es que la obra del Che pertenezca a las letras cubanas, no a las argentinas [Nota al pie del autor: Pertenece a las letras latinoamericanas sin duda; este internacionalismo literario va de la mano con su internacionalismo político. Pocos como el Che apostaron a la identidad latinoamericana como algo más fundamental, previa a las identidades nacionales, en lugar de constituida a posteriori de éstas]. (Gamerro, 2015: 386-387, subrayado en el original)

Y más adelante: "Los escritos del Che han sido propuestos, sobre todo desde Cuba y desde las diversas izquierdas latinoamericanas, como modelo de literatura comprometida, de escritura que lleva a la acción política por el camino más directo" (Gamerro, 2015: 406). Rodolfo Walsh fue, a su vez, uno de quienes conformó la plantilla inicial de periodistas de Prensa Latina, la agencia de noticias creada en 1959 a instancias de Fidel Castro y Ernesto Guevara, con sede central en La Habana, por lo que en cualquier caso se trata de dos figuras cuyas trayectorias confluyen en varios sentidos.

En la novela de Gamerro, el secreto de Estado aparece cifrado, sugestivamente, en una memoria personal e íntima: un diario. No obstante, este depósito endeble, recóndito e individualizado de la suerte de una nación se ve redoblado en la fragilidad de su soporte material: en medio de la guerra, y ante el riesgo que corría la suerte de estas notas, el mayor X pide al soldado Emilio Beltrán que recuerde, literalmente, cada parte de su diario (que se convertiría así en un diario de guerra). Lo que no considera el mayor es que el soldado, al igual que el papel o quizás mucho más, se vería expuesto a los peligros bélicos: está claro, esas vidas nunca fueron tenidas en cuenta por los altos mandos, que sometieron a su tropa al hambre, el frío y los castigos (Lorenz, 2009). Emilio salva su vida pero regresa a Buenos Aires con una bala alojada en su cerebro y es ingresado en un hospital psiquiátrico. Allí, recitará monótona y desordenadamente las partes del diario del mayor $\mathrm{X}$, cumpliendo rigurosamente con la orden que le fuera impartida. Lo hará, como decimos, dejando entrever el daño psíquico que la guerra le supuso. No obstante, a Cuervo sólo le 
importa recuperar la información depositada en el soldado, y allí va, al hospital, a descifrar ese lenguaje afásico. El apellido elegido por el autor no es gratuito: Cuervo planea sobre los despojos.

Emilio es, además, el único sobreviviente de su pelotón, al que los excombatientes llaman 'pelotón fantasma'. Al igual que en la novela de Fogwill, Los pichycyegos (primera novela sobre el conflicto, escrita durante los días finales de la guerra y publicada al año siguiente, en 1983; cf. Gamerro, 2015: 441-448), la memoria recae en un único sobreviviente, testigo por tanto irremplazable, aunque necesariamente insuficiente (Agamben, 2000: 13-40). Sin embargo, la fantasmática presencia de Emilio está mucho más cerca de la esfera de existencia de sus desaparecidos compañeros de pelotón (esto es, una muerte nebulosa, sin duelo posible porque no ha habido funerales, ni recibimiento oficial, ni honores, ni -en la mayoría de los casos- un cuerpo al que rendir tributo), a diferencia del narrador de la novela de Fogwill. Cuando los excombatientes lo visitan, intentan desentrañar los 'enigmas insondables' de su memoria: antes de 'darse por vencidos' -el cruce de imágenes entre esta batalla por rescatar el relato de Emilio y las batallas por Malvinas es magistral en la narración- consiguen comprender la referencia a la leyenda del tatú cordobés, sobre la que volveré más adelante.

La primera entrada que presenta el diario del mayor X corresponde al día 21 de mayo de 1982. La guerra se desarrolló entre el día 2 de abril, desembarco de las fuerzas armadas argentinas en el archipiélago, y la rendición del 10 de junio; esto es, poco más de dos meses. El fuego fue abierto tras el desembarco inglés, el primero de mayo; dicha entrada se produce, pues, en el fragor de la batalla. No obstante, el mayor anota con mirada extrañada:

Decidimos instalarnos en un edificio que dimos en llamar 'la escuela' por su similitud con las nuestras, aunque no comprendo la función que pueda tener para los habitantes nativos. Primeros contactos: intenté hablarles en todas las lenguas principales, entre ellas el castellano, el portugués, el latín, [...] el italiano y gracias a un soldado del R5 hasta hebreo, que para mi gran alivio no comprendían; había llegado a temer que esta colonia fuera uno de los fatídicos 'kibbutz' [...]. En esa perplejidad estaba cuando escuché unos sonidos guturales a mis espaldas, tan disímiles a los de cualquier lengua humana conocida que al principio supuse la intrusión de un bromista, pero cuál no sería mi sorpresa cuando observé los taciturnos rostros de los nativos iluminarse en respuesta y empezar a hablar todos a la vez en los mismos acentos agrestes. Me volví, para ver cuál de mis hombres era responsable. [...] Al ser interrogado el soldado explicó que en unas islas al norte se habla una lengua similar, que él había aprendido en sus viajes. Increíble como pueda parecer la noticia, el hecho indudable es que se comunica con ellos, y desde hoy lo incorporé a mi compañía en calidad de lenguaraz. (Gamerro, 1998: 443-444) 
La referencia a un elemento conocido tomado como analogía para nombrar lo desconocido, el mismo acto de nombrar, la designación de un lenguaraz o la previsión de llevar un políglota en la tripulación remite, en tono paródico, a las crónicas de Indias. A ello se suma el anacronismo en la negación del mayor, por desconocimiento, del idioma inglés como lengua principal, hecho que subraya su bajo nivel de formación cultural (inferior, además, al de su subordinado): aquí también hay una referencia satírica a las circunstancias tanto de la guerra de Malvinas como de la Conquista, en las que participaron, y muchas veces con roles preponderantes, hombres de escasa formación cultural.

En siguientes entradas el diario parodia también el discurso antropológico, describiendo hábitos, religión, economía, leyes, relaciones de parentesco, forma de gobierno: "Su sistema de gobierno, si es que tal puede llamársele, corresponde a la forma más primitiva, la republicana; la perfecta igualdad que reina entre los individuos retrasará por mucho tiempo su civilización" (Gamerro, 1998: 446). La ironía subraya el presupuesto ideológico del mayor: su ideal patriótico es el de una sociedad de clases, y el origen histórico lo sitúa en coincidencia con la Argentina políticamente emancipada, rasgos que se suman a la nota de antisemitismo de la cita anterior. El sarcasmo de su discurso remite nuevamente a la conquista de América, esta vez en contrapunto con la historia del desembarco argentino en 1982, cuando el dictador Galtieri decidió tomar las islas de manera sorpresiva e izar la bandera argentina. Ante aquel hecho, los isleños no presentaron mayor resistencia ya que conocían muy bien la situación política en el continente. Decidieron, en cambio, esperar órdenes de Londres. El mayor da su personalísima lectura de la situación: "Desde el inicio, nos han tributado el respeto y el temor que se concede a los dioses, más que a los hombres, cualesquiera sean su rango y autoridad. [...] Más que nuestras armas, fueron el ejemplo de nuestra organización y disciplina las que nos abrieron las puertas de su isla" (Gamerro, 1998: 447).

Más adelante, otras características de las crónicas de Indias son calcadas, reforzando la parodia en sentido doble: como crítica mordaz tanto a la conquista como a la última dictadura; aquí late la lectura que David Viñas hizo del avance del Estado argentino sobre los pueblos originarios, al que llamó "etapa superior de la conquista española" (Viñas, 2003: 45-62), concibiendo una continuidad entre el proceder colonial y el republicano -y parafraseando, claro, a Lenin en su El imperialismo, fase superior del capitalismo). Un ejemplo de esto es la superioridad con la que se observa a los nativos (cf. cita anterior), el uso de armas de fuego para mantenerlos aterrorizados o la evangelización -muy enlazada a la nacionalización, en este caso:

Por la tarde, y a pesar de la fuerte llovizna y el viento, decido dar comienzo a los cursos de religión y cultura occidental. Primero el capellán castrense, Fray Esteban Panozzi, llevó a cabo un improvisado catequismo, hablándoles de Dios, que es Uno y Tres; de Nuestro Señor Jesucristo y la Divina Encarnación de la Santa Virgen. A pesar de que el lenguaraz traducía todo a su áspera lengua, los vi mi- 
rarse entre sí más de una vez y sacudir las cabezas, como disintiendo. No será fácil la tarea de hacer llegar la luz del Señor a sus almas sumidas en las tinieblas, y hombres menos templados que nosotros seguramente recularían ante tamaña empresa. Seguidamente, y tras repartir unos humeantes jarros de mate cocido que bebieron con avidez, yo mismo pronuncié una breve arenga en la que los declaré ciudadanos argentinos de pleno derecho, e intenté inculcarles el amor a la madre patria, lo que generó una acalorada discusión, que el lenguaraz me explicó se debía a que algunos insistían en decir padre matria, y los otros en corregirlos. Entendiendo que sus simples mentes eran incapaces de hacer distinciones tan delicadas, les conté fragmentos de la vida ejemplar del Padre de la Patria: su infancia correntina, a la sombra de la histórica higuera; su infalible concurrencia a la escuela, lloviera o nevare; sus tempranas hazañas militares". (Gamerro, 1998: 448449)

La referencia a San Martín, conformada por los tópicos escolares, continúa. La explicación religiosa, incomprensible para los habitantes de las islas que no comparten esa fe, remite a diversas escenas que representan la Conquista, tanto en documentos con mayor peso histórico como en los literarios. Así, en Atau Wallpaj púchukakuyninpa wankan/ Tragedia del fin de Atahualpa leemos:

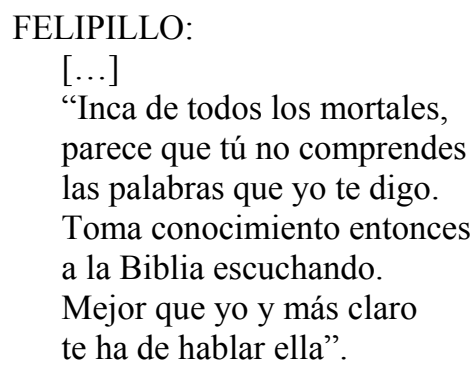

ATAU WALLPA:

No me dice absolutamente nada. (Anónimo, 2005: 131)

En cuanto a la declaración de ciudadanía, que parodia las declaraciones de vasallaje hechas a los habitantes originarios durante la Conquista, hay que señalar que este es un punto particularmente sensible en el conflicto de soberanía en las islas, ya que sus habitantes se reconocen, desde luego, ingleses. La ironía crítica se torna entonces doblemente mordaz, tanto más en un texto publicado tras ridículos esfuerzos de la cancillería argentina bajo el gobierno neoliberal de los años noventa en seducir a los kelpers mediante, por ejemplo, el envío de osos de peluche.

En la siguiente entrada, el diario agrega:

En su simplicidad, los nativos confundieron el catequismo con la lección de historia, y creen que San Martín es uno de los santos del cielo. Lo que es más, creen 
que yo mismo soy San Martín y que vengo del cielo -en este caso, claramente, el helicóptero que nos trajo. Estuve a punto de reunirlos inmediatamente para disipar semejante malentendido, pero luego lo pensé mejor. ¿Qué mal puede hacer esta pequeña confusión, si los mantiene sumisos y bien dispuestos? Mayores mentiras que ésta ha sabido aceptar el Señor para la prosecución de Su causa. (Gamerro, 1998: 449-450)

Tenemos, entonces, un calco burlesco de las crónicas con hincapié en el discurso religioso, pero también una fuerte sátira montada sobre el discurso de las fuerzas armadas, que creían tener por misión 'extirpar el cáncer marxista' del cuerpo social. Como durante la Conquista, la unión de la cruz y la espada está presente de manera tácita o explícita en una causa que encuentra su legitimación última en los mandatos de la 'civilización occidental y cristiana', que pareciera habilitar todo tipo de crímenes.

Por último encontramos también la cuestión del oro, que es central en los Diarios de Colón (Todorov, 2007), primera referencia a la que estos textos parodian por tratarse precisamente de un diario. Dice Colón:

Y yo estaba atento y trabajaba para saber si había oro, y vi que algunos de ellos traían un pedazuelo colgado en un agujero que tienen en la nariz, y por señas pude entender que yendo al Sur o volviendo a la isla por el Sur, que estaba allí un rey que tenía grandes vasos de ellos, y tenía mucho. Trabajé que fuesen allá, y después vi que no entendían la idea (Colón, 2006: 37).

Y el mayor:

En mi ronda, descubrí en la boca de un anciano de gruesos bigotes blancos el brillo del oro, y también en el arete de una jovencita de cabellos del mismo color. Interrogados por el lenguaraz acerca de la procedencia del precioso metal, algunos de ellos señalaron al Norte, repitiendo una palabra que sonaba como 'ingoland' (Gamerro, 1998: 456).

England será interpretado como in gold land, en la tierra del oro, esto es, Eldorado, y llevará el relato hasta su pretendido punto de partida, las Invasiones Inglesas de 1806 y 1807 al puerto de Buenos Aires, que son, desde el punto de vista de la historiografía republicana, el comienzo de la emancipación en los territorios de la actual Argentina. Llegados a este punto es necesario volver, entonces, sobre la leyenda del tatú cordobés. El tatú, también llamado 'tatú carreta', es un armadillo de las pampas, al igual que el pichiciego. La interpretación que el lenguaraz hace de los dichos de los kelpers llevan al mayor a creer que ejercen el trueque con otro grupo, que les daría a cambio el oro. Pero no se trataría de cualquier oro, sino del procedente del tesoro del Cabildo colonial de Buenos Aires, retirado -según recoge la historiografía- por el virrey Sobremonte (último virrey español en el Río de la 
Plata) al invadir la flota inglesa el puerto de Buenos Aires en 1806, y trasladado en carreta con destino a la ciudad argentina de Córdoba: "Al parecer, el tesoro fue traído del continente en tiempos de la colonia, oculto dentro del caparazón de un tatú carreta" (Gamerro, 1998: 458). El disparate, entonces, funciona aquí aun por asociación metonímica, donde tatú/carreta remite a la salida histórica del tesoro.

El mayor decide luego partir en busca de ese botín. Propone a sus hombres acompañarlo, o bien rendirse y regresar como prisioneros de guerra de los ingleses al continente. Poco más de una docena de hombres lo sigue, entre ellos el lenguaraz y el soldado Emilio Beltrán, de memoria prodigiosa, a quien decide confiar el contenido de su diario para ponerlo a buen resguardo. La travesía en busca del tesoro es larga y terrible; en esos pasajes, el intertexto -análisis que no desarrollo aquí- son también los diarios del Che, sus diarios de campaña: Congo, Bolivia, Cuba (Guevara, 1999, 2001, 2007). El 14 de junio de 1982, en coincidencia con la fecha de la rendición de las Fuerzas Armadas argentinas que pone fin a la guerra de Malvinas, es recordado como un día epifánico en el diario del mayor:

Hace dos días, el 14 de junio, el soldado Beltrán y yo, los únicos sobrevivientes del heroico pelotón, avanzábamos por el helado desierto de niebla perenne cuando mis manos estiradas hacia adelante se encontraron con una pared sólida, y tan lisa que no había duda de que se trataba de una fabricación humana. Acerqué a ella los ojos cuanto pude, para ver de qué materia era hecha, y mi asombro no tuvo límite cuando comprobaron que tras la niebla no había más que una interminable transparencia, como si el aire limpio hubiera fraguado en roca sólida para detener su avance. Del interior de esa roca, una voz grave y profunda como no la había escuchado jamás, me saludó en un perfecto castellano, puro y destilado como el aire que lo sostenía:

- Bienvenido, mayor X. Lo estábamos esperando. Bienvenido a la Argentina invisible. (Gamerro, 1998: 467)

Las Islas Malvinas fueron ocupadas por los criollos en 1811 tras la deposición del último virrey y la constitución de la Primera Junta de Gobierno. En 1833, tras una serie de incidentes, la marina inglesa consigue expulsar por la fuerza la pequeña colonia de criollos que residía en las islas (Groussac, 1934: 31-33). Muchos parten hacia el continente pero un grupo de rebeldes, liderados por el gaucho Rivero, permanece allí. Se sabe que finalmente fueron expulsados y enviados a juicio en Londres, donde no se los juzgó ya que la corona británica no reconocía soberanía sobre las islas, por lo que fueron embarcados hacia el Uruguay (Muñoz Azpiri, 1966: 567569). No obstante, en la fantasía del mayor, este grupo nunca abandonó las islas: sus descendientes son quienes reciben con asado y vino a estos dos personajes, y ponen al corriente de la historia al orgulloso mayor:

Un gaucho impecablemente ataviado, con las facciones de Lugones, le abrió a Cuervo las puertas de la Gran Estancia Nacional, donde los dos únicos famélicos 
sobrevivientes fueron recibidos con una fastuosa parrillada asada con madera de ceibo en parrillas de oro puro. Cientos de próceres vestidos a la usanza tradicional compartían las largas mesas de algarrobo con incrustaciones de ónice. La comunidad argentina ideal, le contó el poeta mientras comían a mano y facón, entre sorbo y sorbo de vino purpúreo servido en astas de toro recamadas en plata exquisitamente labrada, había sido fundada por los argentinos residentes en Malvinas tras la ocupación de las islas en 1830. En su forzado exilio hacia el interior de la Isla Grande habían encontrado el tesoro del tatú cordobés (que, rampante, se erigía sobre un altar de piedras preciosas en medio del salón-quincho) y comprendiendo que la patria grande se vería siempre acosada por las corruptas corrientes de la historia y el mundo exterior, habían decidido fundar esta ciudadela inexpugnable en el corazón de las islas, para mantener pura la esencia patria y desde allí manejar los destinos nacionales con mano invisible. Cada vez que la patria se encontraba en peligro, en cada encrucijada del destino nacional, ellos acudían en su ayuda. Se decían descendientes del Homo argentinus descrito por Florentino Ameghino (uno de los tantos próceres que ellos habían guiado con sus voces) e incontaminados de cualquier influencia extranjera o inmigración habían destilado la esencia de la sangre y la lengua argentinas manteniendo su pureza hasta el presente. (Gamerro, 1998: 468)

Aquí están condensadas las ideas que legitimaron el statu quo nacional desde el último tercio del siglo XIX, en que vence el proyecto de nación vigente. El grupo, que reúne al panteón de próceres mediante cuyas biografías se ha escrito la historia oficial en Argentina, aquel que reconvirtió la tradición militar nacional de escuela napoleónica sanmartiniana en escuela prusiana (Horowicz, 2011: 15), está encabezado por Lugones, el poeta nacional por antonomasia, que proclamó además "la hora de la espada" en 1824, centenario de la batalla de Ayacucho, y fue uno de los ideólogos del golpismo antipopular desatado en $1930^{1}$. Este reducto funciona no sólo como alegoría de la patria soñada por la generación del 80 sino como la encarnación de los ideales promovidos por las Fuerzas Armadas, que funcionaron desde aquella proclama de Lugones como garantía última de los intereses del partido del Estado, esto es, la clase dominante, el partido constituido por los grupos económicos. El partido de Estado puede coincidir o no con el partido de gobierno, que se define, en cambio, "en relación con el arco social que lo votó. Está determinado por su adhesión social a una política" (Horowicz, 2012: 47). Los frecuentes golpes de

${ }^{1}$ Su hijo, jefe de policía durante esa primera dictadura del siglo XX, fue quien inventó la picana eléctrica, el instrumento de tortura que caracterizó a la represión en Argentina. La nieta del poeta e hija de este comisario, Susana "Pirí" Lugones, escritora y periodista, fue pareja de Rodolfo Walsh y una de las desaparecidas bajo la dictadura militar de Videla. Se presentaba en vida como "nieta del poeta, hija del torturador", y le cupo en suerte padecer lo que aquellos habían promulgado. 
Estado en Argentina a lo largo del siglo XX fueron producto de la no coincidencia entre partido de Estado y partido de gobierno.

La Argentina ideal aparece representada como una gran estancia, sinécdoque privilegiada de la patria terrateniente ganadera y agroexportadora, habitada sólo por hombres que comen, como los gauchos, asado con facón. El ceibo es, por lo demás, la flor nacional; la parrilla es de oro puro, por lo que la carne se asa sobre el recuperado tesoro del Cabildo; el algarrobo, las astas de toro, el quincho y otros elementos de cepa criolla completan el cuadro en clave nacionalista. Lo fundamental aquí es que el corazón de la patria aparece colocado en medio de las islas; bajo esta mirada racista y clasista, la "pureza" en términos lingüísticos, religiosos y culturales está resguardada allí. El paralelismo gaucho/patriota, propugnado por Lugones y Rojas a comienzos del siglo XX, frente a inmigrante/apátrida, se ve aquí continuado por la línea Fuerzas Armadas frente a marxismo. No obstante Malvinas fue, de manera paradójica, el núcleo que rompió esta dicotomía histórica y supo funcionar como aglutinante nacionalista (Rozitchner, 2006).

Este androceo perfecto posee, además, un peculiar mecanismo de reproducción. Para evitar todo tipo de contaminación, han prohibido la entrada de mujeres al clan porque "con la mujer hacen su entrada la duplicidad y el disenso" (Gamerro, 1998: 469), hecho que tensa la máxima patriarcal que rigió en la Argentina de aquellos años. Hacen, entonces, uso del vientre de las kelpers para clonarse en ellos, y de sus cuerpos para la satisfacción sexual (cf. con otra disparatada propuesta, en Márques, 2000). Por último, Lugones informa al mayor acerca de la misión secreta que le toca cumplir: en su delirio de grandeza, que recuerda, sin más, a Galtieri, el mayor se sueña elegido 'el nuevo San Martín' que consigue la rendición inglesa el 20 de junio, Día de la Bandera en Argentina. Comenzando por Gran Bretaña, uno tras otro los pueblos del mundo son sometidos al mandato de este vencedor, y del Proceso de Reorganización Nacional, nombre dado por la junta militar al golpe de Estado de 1976, se concluye en el "Proceso de Reorganización Mundial" (Gamerro, 1998: 472). De este modo, las Fuerzas Armadas cumplen otra vez con el mandato de preservar la patria, extendiéndose además hacia un orden mundial que remite directamente al imperialismo y el colonialismo, por lo que esta fantasía utópica de victoria invierte la marca que dejó la guerra de Malvinas en la historia de esas fuerzas. El hecho tendría su anclaje, además, en las -entonces sí- contenidas invasiones inglesas por parte de los habitantes de Buenos Aires.

Un diario es un documento histórico. Su letra construye una memoria, en este caso de Estado. Un escrito es una pieza privilegiada en la (re)construcción del pasado. El diario del mayor proyecta en victoria lo que fue una rotunda derrota; reinventa un nuevo origen en el contacto con las islas, un desembarco fundacional que desconoce y niega cualquier otra toma de contacto por parte del Estado argentino. Lo hace, claro, sirviéndose del discurso de la Conquista de América, lo cual remite a la señalada lectura de Viñas. Lo interesante aquí es que, para el borramiento de la derrota, se respalda en un género que -en líneas generales, y con las vicisitudes que 
conocemos- narró una victoria: de occidente, de la cristiandad, de la corona, por sobre los pueblos colonizados. La utopía de victoria que despliega el relato del mayor $\mathrm{X}$ condensa en negativo una terrible paradoja nacional, que es ya el leitmotiv de una época: 'hubo que perder la guerra para recuperar la democracia'. Si bien el diario del mayor decide que la guerra fue ganada, y por tanto también la continuidad de la dictadura, lo cierto es que no sería ni siquiera necesaria esa ficticia victoria, ya que por muchos años más, la calidad de democracia en Argentina haría de Felipe Félix un hermano literario de Stephen Dedalus: desde la posdictadura de fines del siglo XX, mejor conocida como 'democracia de la derrota' (Horowicz, 2012: 335-370), la historia fue una pesadilla de la que se intentó despertar una ferviente noche de diciembre de 2001.

\section{BIBLIOGRAFÍA}

AgAMBEN, Giorgio.

2000 Lo Que Queda de Ausschwitz. El Archivo y el testigo. Homo Sacer III. Valencia: Pre-Textos.

ANÓNIMO.

2005 Tragedia del fin de Atahualpa: Atau Wallpaj púchukakuyninpa wankan. Jesús Lara (ed.). Buenos Aires: Del Sol.

BAUER, Tristán.

1997 Eva, una tumba sin paz. Argentina [film].

COLÓN, Cristóbal.

2006 Los cuatro viajes del Almirante y su testamento. Madrid: Espasa Calpe.

FOGWILL, Rodolfo.

1983 Los Pichy-cyegos. Visiones de una batalla subterránea. Buenos Aires: Ediciones de la Flor.

GAMERRO, Carlos.

1998 Las Islas. Buenos Aires: Simurg.

2004 La aventura de los bustos de Eva. Buenos Aires: Norma.

2011 Un yuppie en la columna del Che Guevara. Buenos Aires: Edhasa.

2015 Facundo o Martín Fierro. Los libros que inventaron la Argentina. Buenos Aires: Sudamericana.

GUEVARA, Ernesto.

1999 Pasajes de la guerra revolucionaria: Congo. Barcelona: Mondadori.

2001 Diario del Che en Bolivia. La Habana: Ciencias Sociales.

2007 Pasajes de la guerra revolucionaria. La Habana: Ocean Sur.

GroussaC, Paul.

1934 Las islas Malvinas. Buenos Aires: Biblioteca Nacional.

HOROWICZ, Alejandro.

2011 Los cuatro peronismos. Buenos Aires: Edhasa. 
2012 Las dictaduras argentinas. Historia de una frustración nacional. Buenos Aires: Edhasa.

HUTCHEON, Linda.

1981 "Ironie, satire, parodie. Une approche pragmatique de l'ironie", en Revue Poétique, núm. 46, 1981, pp. 140-155.

KOHAN, Martín.

1999 "El Fin de Una Épica”, en Punto de Vista, núm. 64, 1999, pp. 6-11. LORENZ, Federico.

2009 Malvinas. Una guerra argentina. Buenos Aires: Sudamericana.

MARQUES, José Luis.

2000 Fuckland. Argentina [film].

MUÑOZ AZPIRI, José Luis.

1966 Historia completa de las Malvinas. Buenos Aires: Oriente.

PERLONGHER, Néstor.

1997 Poemas completos (1980-1992). Buenos Aires: Compañía Editora Espasa Calpe Argentina S.A./Seix Barral.

PIGLIA, Ricardo.

2005 El último lector. Barcelona: Anagrama.

ROZITCHNER, León.

2006 Las Malvinas: de la guerra «sucia» a la guerra «limpia». Buenos Aires: Losada.

TODOROV, Tzvetan.

2007 La Conquista de América. El problema del otro. México: Fondo de Cultura Económica.

VIÑAS, David.

2003 Indios, ejército y frontera. Buenos Aires: Santiago Arcos.

VV.AA.

1982 Cronistas de Indias. Antología. Buenos Aires: Colihue.

WALSH, Rodolfo.

1996 Los oficios terrestres. Buenos Aires: Ediciones de la Flor. 